\title{
The Role of Monetary Incentives: Bonus and/or Stimulus
}

\author{
Linda Ponta ${ }^{1, *(\mathbb{D} \text {, Francesco Delfino }}{ }^{2}$ and Gian Carlo Cainarca $^{2}$ \\ 1 School of Engineering, LIUC-Cattaneo University, Corso G. Matteotti 22, 21053 Castellanza (VA), Italy \\ 2 Department of Mechanical, Energy, Management and Transportation Engineering, University of Genoa, \\ Via Opera Pia 15, 16145 Genoa, Italy \\ * Correspondence: lponta@liuc.it
}

Received: 8 November 2019; Accepted: 21 January 2020; Published: 5 February 2020

check for updates

\begin{abstract}
In this paper, the role of the monetary incentives in the employee performance is investigated in the context of Public Administration (PA). In particular, the distribution of monetary incentives among the employees based on the position held, is compared with a merit approach which tends to recognize and reward individual contributions. Starting from a questionnaire, the informal network, which ignores the vertical relation among supervisor and employees, is created and a Centrality Index, based on the employee connections, has been defined and used to proxy the performance of employees. The main goals of the paper are to understand if the two mechanisms of monetary incentive distribution affect the employee performance, to analyze the variables that influence the employee performance, and therefore to identify the role of monetary incentives. The linear regression methodology has been chosen as a tool of analysis. Results show that the distribution of monetary incentives according to merit criteria rewards the employee performance and has positive effects on the employee performance in the short term.
\end{abstract}

Keywords: public administration; monetary incentives; organization; network

\section{Introduction}

In the last 30 years, many reforms of the public sector have been guided by the New Public Management (NPM) theory. NPM is a theory on how the public sector is to be governed, developed by political scientists working in the field of public administration in the UK and Australia in the early 1990s (Hood 1991; Hood and Jackson 1991). This theory contains insights from game theory and from the disciplines of law and economics. In the decade after entering the literature, NPM acquired a wider range of meanings.

One of the main key ideas of the NPM is that public sector organizations need to introduce performance management based on targets, monitoring and incentives (Cainarca et al. 2019; Hood 1995). In other words, in the Public Administration (PA), a performance improvement requires a transition from a "bureaucratic culture" to a results-oriented one that emphasizes outcomes rather than inputs or processes. Reform initiatives, concerning the performance appraisal and reward systems, could foster technical (use of output controls and explicit standards performance) as well as cultural (managerial accountability and responsibility for action) changes in the public sector (Gruening 2001; Hood 1991).

Since the early 1990s, many transformation attempts with the adoption of new managerial instruments, which are often borrowed from the private sector, have been made, but the transferability of tools generally used in the private sector to the bureaucracy of the PA is not always possible. Focusing on incentives and, in particular, on monetary incentives, the balance reached by operating on their architecture has been enriched with all those conceptual tools that research into Human Resource Management (HRM) has developed over time. The ability to identify the consequences of the incentives scheme design to be adopted is highly dependent on how services are defined 
and measured Levitats and Vigoda-Gadot (2019). In the literature, particular attention is devoted to the application of extrinsic incentive mechanisms, but without reaching conclusive results Perry et al. (2009). According to Perry et al. (2009), Performance-Related Pay (PRP) has failed to produce the expected changes. It is worth remembering that a variety of contextual factors moderates the effectiveness of PRP, such as organizational context, scheme design, performance indicators, form of the incentive Spano and Monfardini (2018) and the application of PRP to public services often encounters some resistances due to the non-market logic of government organizations (Atkinson et al. 2014; Bellé 2015; Frey et al. 2013; Weibel et al. 2009).

Moreover, the problems of PA are the constraints that reduce the possibility to make change if they are not imposed by law.

In Italy, next to the initiatives already implemented (for example, training), an attempt to initiate a virtuous circle able to trigger behaviors (for example, improving the efforts) more efficient can be seen in the introduction of the "Decreto Legislativo 27 ottobre 2009, n. 150", "Attuazione della legge 4 marzo 2009, n. 15, in materia di ottimizzazione della produttività del lavoro pubblico e di efficienza e trasparenza delle pubbliche amministrazioni. (09G0164)". According to this law the monetary incentives are distributed ranking the employees according to merit criteria.

It is worth noting that the promotion tournaments in public organization hierarchies might be more efficient than pay-for-performance systems (Weibel et al. 2009; Whitford 2006). The main goal of the paper is to study the actual and potential impact of economic incentives on individual performance in Public Administration (PA). In particular, the paper investigates if the introduction of a meritocratic-based system of monetary incentives which tends to recognize and reward individual contribution in the PA really rewards the employee performance and if it is a stimulus for better employee performance in the future period of evaluation. In other words, the main research questions are to test whether the introduction of a competitive system, structured as a "closed-ranks tournament", encourages employees (non-managers) to improve their performance and whether it induces virtuous behavior in employees. The results show that a well-suited design scheme of economic incentives like the meritocratic-based system has positive effects on individual performance, rewarding the employee performance and creating a stimulus in the short term. To address such investigation, thanks to the availability of empirical data collected by two questionnaires, the paper presents an empirical analysis. Many models can be used to perform this analysis for example the data envelopment analysis (DEA) or linear and nonlinear regressions (Blalock 2017a; Gordon 2015). DEA is a nonparametric method in operations research and economics used to empirically measure productive efficiency of decision-making units (DMUs) Mariano et al. (2015). In this paper, the linear regression methodology has been chosen. It is worth noting that linear models, their variants and extensions, are among the most useful and widely used statistical tools for social research (Blalock 2017b; Fox 1997). The paper is organized as follows: Section 2 presents a literary review defining the research scope and the research hypotheses, Section 3 the empirical data, Section 4 the model, Section 5 shows the results of the empirical analysis. Finally, Section 6 provides the discussion and conclusions of the study.

\section{Literary Review and Research Hypothesis}

In the literature, many scholars underline the difficulty to define how to increase and evaluate the performance of employees (Boland and Fowler 2000; Brignall and Modell 2000; Johnsen 2019; Shields et al. 2015; Umans et al. 2018) in general, and in particular in the Public Administration (PA) (Behn 1995; Burgess et al. 2017; Kearney 2018; Koliba et al. 2017). Many theory have been developed and the most important are the Public Service Motivation (PSM), the Organizational Citizenship Behavior (OCB) and the ones based on the Ability and Motivation model and the Ability, Motivation and Opportunity (AMO) model. According to the Public Service Motivation (PSM) the most important aspect for the employee performance is the intrinsic motivation, whereas for the OCB the employee performance cannot be evaluated considering only the job description. Organizational Citizenship Behavior (OCB) represents a concept that describes a person's voluntary commitment that is not part of her/his contractual 
tasks (Alkahtani 2015; Mostafa et al. 2015; Organ 1988; Perry 1996; Perry and Vandenabeele 2015; Perry and Wise 1990; Rainey 2009; Ritz et al. 2016; Sawitri et al. 2016; Smith et al. 1983). According to the Ability and Motivation model, a person's "capacity to work" and "will to work" jointly determine her/his level of performance (Mace et al. 1935; Viteles 1953; Yating and Yang 2017). The main theories formalize "capacity to work" as ability and the "will to work" as motivation (Maier 1955; Marin-Garcia and Tomas 2016). Thus, employees perform better, if they possess the necessary knowledge and skills, they do the job because they want to and are adequately motivated. There could be an individual who is motivated, but without the requisite ability to perform and there may be an individual with knowledge and skills but little motivation. To improve the effective evaluation of the contribution of employees, this model has been enriched adding a new component: the opportunity to perform. The resulting model has been called Ability, Motivation and Opportunity (AMO) model (Appelbaum 2000; Paauwe 2009). According to this logic, HR system, designed to maximize employee performance, is viewed as a composition of three dimensions intended to enhance employee skills, motivation, and opportunity to contribute, respectively (Appelbaum 2000; Boxall and Purcell 2008; Delery and Shaw 2001; Katz et al. 1985; Lepak et al. 2006). Thus, employees perform better, if they can do the job because they possess the necessary knowledge and skills (Abilities, A), they do the job because they want to and are adequately motivated (Motivation, M) and their work environment provides the necessary support and avenues for expression (Opportunity to participate, O) (Brayfield and Crockett 1955). Focusing on the motivation component, it is worth noting that it is already known that the employee performance is modified using economic motivation (Banno and Sgobbi 2010). The use of monetary or other financial incentives in the classic performance paradigm is based primarily on the theoretical propositions of reinforcement theory (Durant et al. 2006), of expectancy theory (Pearce and Perry 1983) and performance-related pay theory. Reinforcement theory focuses on the relationship between the target behavior (e.g., performance) and a motivational tool (e.g., pay for performance) (Skinner 1969). It is premised on the principles and techniques of organizational behavior modification (Luthans 1973; Skinner 1969; Stajkovic and Luthans 1997). Expectancy theory is predicated on a belief that individuals exert effort if they expect it will result in an outcome that they value (Van Eerde and Thierry 1996). In the case of performance-related pay, employees work harder if they value monetary rewards and believe that those awards will result from their increased efforts (Lah and Perry 2008; Salzman 2000). PRP, contrary to a mechanism that pay a bonus based on seniority, represents a tool that is capable of boosting work motivation, increasing the performance of employees Chang (2011). It is worth remembering that the performance-related pay is not invention of NPM, but is connected to principles of Weberian bureaucracy, see (Dahlström and Lapuente 2017) for further details. Finally, it is worth remarking that numerous studies in the literature argue that the effectiveness of monetary incentives is linked to the particular conditions of the organization and in particular that usually, individual economic incentives are not so effective in traditional public sector settings (Durant et al. 2006). The evidence offered by the literature in this context is very variegated (Perry et al. 2009); only in some contexts, for example medical and education, is its effect positive (Andersen 2007; Davidson et al. 1992; Dowling and Richardson 1997; Shaw et al. 2003). It is worth noting that this is true in corporate contexts as well Mao and Weathers (2019).

The aspect that makes hard to interpret the relationship between incentive and performance is linked to the identification of the contribution of individual employees. If this is easier in private firms, where the results of operations are clear, it is more difficult in the public sector, where profit is not the primary goal. If it is not possible to locate certain criteria and uniform evaluation for employees, the evaluation schemes should be designed to capture the different levels of competence and predisposition of individuals to exert a greater effort in the workplace.

There are several ways to detect the performance of employees (Bradler et al. 2016; Lăzăroiu et al. 2015). The most common measure considers the subjective evaluations that take account of individual organizational behavior or the objective, directly considering the feedback of one or more superior or all of the colleagues who have contact with the individual employee. To overcome the limits of a subjective measure, an objective evaluation of the importance and relevance that a single employee has, 
compared to their colleagues is possible by using the network analysis and in particular the connections among the employees. In fact, the intra-organizational relationships reflect the recognition given to a single employee from her/his colleagues for her/his skills and her/his opportunities to participate in working life (Bonacich 1987; Freeman 1977).

\subsection{Network Centrality and Performance}

Generally speaking, centrality indicates the influence of an individual within a network regarding other individuals within that network Brass and Burkhardt (1992). Thus, using the network analysis approach, the centrality in the advice network is considered to be proxy of individual performance Boissevain and Mitchell (2018). The exchange of task advice and information is likely to be positively related to job performance. Individuals share information, advice and assistance, in connection with their work. Centrality in the advice network means the involvement of each individual in the exchange of assistance with other colleagues and availability to put effort into problem solving. A central individual can accumulate knowledge about many problems over the years, and as others become dependent on a central individual for some important advices, she/he gains power and authority Baldwin et al. (1997); Cook et al. (1983). Although there are many definitions of centrality, the most common are the Degree, the Closeness, Betweenness and the Bonacich centrality Aalbers and Dolfsma (2015). The degree centrality is defined as counting the number of in- and out-/or outgoing ties from one's position within the network. This is an intuitive measure: more contacts means more actors one can draw on. Since contacts may not be reciprocal, it makes sense to distinguish in-degree from out-degree. This is the simplest way to measure the importance of a node in a network Lü et al. (2016).

Recently, some scholars argued that the location of a node is more significant than the number of its linked neighbors, and they suggested that coreness is a better indicator of a node's influence on spreading dynamics than degree. The coreness of a node is measured by k-core decomposition, and a larger coreness value indicates that the node is more centrally located in the network Kitsak et al. (2010). The closeness centrality, instead, assesses the "distance" of a person to all other persons in a network. Closeness centrality is an intuitive measure of how well (quick) one can actively spread information oneself or become aware of information, rumors and epidemics spread by others through the network (defined as the total number of steps of the actor to all the other reactors). The betweenness centrality assesses the extent to which one is positioned on the shortest path between any pair of any two of one's colleagues in the network. Betweenness centrality is an intuitive measure of how one plays a role as go-between, broker, or structural hole. In addition to Degree, Betweenness and Closeness Centrality, Bonacich centrality is an intuitive measure of the status that someone has since it takes into account the number of onward ties someone an agent is connected with has. One's centrality score is based on one's neighbors' centrality. A higher centrality of this variety indicates strong control over one's direct contacts, and the contacts of these contacts.

Centrality is also used in studying innovation in an organization (Ibarra and Andrews 1993).

\subsection{Monetary Incentives Mechanisms in PA}

So far, the monetary incentives in the public sector, were distributed equally among the business units, and then divided among the single employees according to a hierarchical logic, i.e., with a fraction proportional to the tenure, predetermined according to the role in the organization. An attempt to introduce a merit logic in the distribution of monetary incentives in the PA is represented by the Italian Legislative Decree no.150/2009. Italian Legislative Decree no.150/2009 states that public administrations, must promote merit and performance improvement using selective reward systems. Employees who achieve the best performance should be rewarded through the selective allocation of economic and career incentives. The introduction by decree of a closed-ranks tournament system could be an efficient way of labor compensation when measuring the performance of individual employees is more difficult than organizing them through ranking. However, little research has been developed 
about the use of rank-order tournaments in the public sector. According to this theory, wage differences are based not on marginal productivity but instead upon relative differences between the individuals Lazear and Rosen (1981). Furthermore, this system could overcome the problem of budget constraint, since the ability of employees to increase their bonus (earning it at the expense of someone else) is not limited. Rank-order tournaments represent a system of nonlinear bonus given because each additional unit of performance does not necessarily translate into an additional unit of reward Whitford (2006). The intention of those who apply this incentivizing system is to produce positive results continuously, discouraging people from taking opportunistic attitudes. Managers who create the tournament rules seek to discourage risk-aversion, affirmation of which would lead instead to a crystallization of the system. This would cause a double negative effect: the less efficient employees will not be stimulated to improve, considering the required results out of reach, while the most deserving ones will consider a performance just enough to be rewarded, beating their colleagues of the lower classes. After the first year, the distribution of bonuses will form an incentive for the performance of the following year.

\subsection{Research Hypothesis}

Based on the above discussion, the two research hypotheses of this investigation claim that:

Hypothesis 1. The monetary incentives, distributed according a merit approach which tends to recognize and reward individual contribution rewards the employee performance.

Hypothesis 2. The monetary incentives distributed according a merit approach which tends to recognize and reward individual contribution are a positive stimulus to improve the employee performance of the next period of evaluation.

In the first hypothesis the mechanism of monetary incentives' distribution base on merit is studied, whereas in the second the effect of this mechanism is investigated.

\section{The Data}

The PA considered in this investigation is an Italian chamber of commerce. The chambers of commerce are public bodies focused on the needs of local businesses; their primary mission is to work as a key component of the local economy, in particular they perform functions of general interest for all kinds of companies and entrepreneurs and focus on the development of local economies. They are autonomous bodies, as each of them has its own statute, management and policies, and they are also financially independent. The reform of the chambers of commerce is found in Law no. 580 of December 29th, 1993, as amended by Legislative Decree no. 219 of November 25th, 2016. The main functions are summarized in Table 1

Table 1. Main functions of Italian chambers of commerce.

\begin{tabular}{cl}
\hline \multicolumn{1}{c}{ Functions } & Description \\
\hline Administrative services & $\begin{array}{l}\text { keeping and updating the Business Register, the Register of Protests, } \\
\text { the Register of Assessors and Experts, the Patent and Trademark Register }\end{array}$ \\
\hline Promotional services & $\begin{array}{l}\text { providing information and financial support to the local business } \\
\text { community }\end{array}$ \\
\hline Information for economic analysis & $\begin{array}{l}\text { providing lists of businesses for market analysis, studies and analyses } \\
\text { based on local economic data }\end{array}$ \\
\hline Market regulation & $\begin{array}{l}\text { increasing market transparency by promoting the spread of fair, } \\
\text { well-known rules and correct trading practices, to build up mutual trust } \\
\text { between consumers and entrepreneurs }\end{array}$ \\
\hline
\end{tabular}

The period of investigation is from year 2010 to year 2013. This period has been chosen because in Italy in 2009 the D.L.150/09 has been introduced and the mechanism of distribution of monetary incentives in PAs changes. 
Two surveys were conducted in February 2011 and January 2013. The method of semi-structured interviews has been used. 131 employees in February 2011 and 126 in January 2013 belonging to a local PA were interviewed. The employees, organized in five Organizational Area and 16 units, participated in one-hour face-to-face interviews composed by 57 questions with answer that ranges between 1 to 7 according the Likert scale (Albaum 1997).

Table 2 summarizes the organization and activity of each area.

Table 2. Area and business units description. The data refers to year 2013.

\begin{tabular}{ccccc}
\hline Area Number & Area and Sectors & Employees & \% Women & Average Age \\
\hline 1 & Support services, staff e personnel & 23 & $74 \%$ & 47 \\
\hline & Presidency and studies & 2 & $100 \%$ & 58 \\
& General Secretariat & 2 & $100 \%$ & 45 \\
& Tourism and external relations & 3 & $100 \%$ & 52 \\
& Administrative and documentation support services & 6 & $67 \%$ & 44 \\
& Staff and organization & 10 & $60 \%$ & 47 \\
\hline 2 & Internal services & 23 & $48 \%$ & 49 \\
\hline 3 & Statistical & 2 & $100 \%$ & 48 \\
& Accounting and budget & 7 & $57 \%$ & 50 \\
& Inspectorate & 14 & $29 \%$ & 51 \\
\hline 4 & Personal data services & 37 & $68 \%$ & 52 \\
\hline Companies Register & 24 & $67 \%$ & 53 \\
& Environment and special ratings & 8 & $63 \%$ & 52 \\
& Chiavari & 5 & $80 \%$ & 49 \\
\hline 5 & Promotional activities & 21 & $81 \%$ & 49 \\
\hline & Productive Activities & 5 & $80 \%$ & 54 \\
& Economic development & 4 & $75 \%$ & 47 \\
& Logistics & 4 & $50 \%$ & 47 \\
& Internationalization & 8 & $100 \%$ & 49 \\
\hline & Area regulation of the market & 17 & $53 \%$ & 51 \\
\hline Market regulation services & 10 & $70 \%$ & 49 \\
& Metric and inspection services & 4 & $0 \%$ & 51 \\
\hline & Innovation & 3 & $67 \%$ & 55 \\
\hline
\end{tabular}

The questionnaires were administered directly by the research team to the employees to minimize misunderstandings, highlighting their anonymity, the use of data for research and the agreement with the trade unions. The effective number of questionnaires collected in 2011 is 126 because four employees were absent and one was appointed as temporary secretary; in 2013, the number is 121 . It is worth noting that the total number of employees decreases because of some retrieves and the financial crisis. The questionnaire was composed by the following main parts:

- personal data of the interviewees (age, gender),

- the occupied position (tenure, organizational area),

- the skills (problem solving, team working, determination, customer oriented, self-organizing),

- intra-organization relationships.

Table 3 summarized the questionnaire's structure.

The resulting database provides information on the personal data (the position occupied, the knowledge and skills and the background of the interviewee), on the organizational model (the relations inter and intra-organization) and the technology used. 
Table 3. Questionnaire.

\begin{tabular}{|c|c|c|}
\hline Questionnaire's Sections & Description & Questions about \\
\hline A & Personal Data & $\begin{array}{l}\text { Employees personal data such as age, } \\
\text { qualification }\end{array}$ \\
\hline B & Position held in the organization & $\begin{array}{l}\text { The duties covered by the worker, in terms } \\
\text { of characteristics, sector of belonging, type } \\
\text { of professional classification }\end{array}$ \\
\hline $\mathrm{C}$ & Organizational model & $\begin{array}{l}\text { How processes are managed and organized, } \\
\text { autonomy, supervision, clarity of information }\end{array}$ \\
\hline $\mathrm{D}$ & Inter-and intra-organization relations & $\begin{array}{l}\text { The relationships between internal and } \\
\text { external subjects }\end{array}$ \\
\hline $\mathrm{E}$ & Technologies & $\begin{array}{l}\text { How the technologies are used and their } \\
\text { impact on the performance of the job) }\end{array}$ \\
\hline $\mathrm{F}$ & Knowledge and skills & Workers' knowledge and skills \\
\hline G & Training & Training within the organization \\
\hline $\mathrm{H}$ & Internal environment & $\begin{array}{l}\text { Aspects concerning the organizational } \\
\text { climate and the working environment. } \\
\text { In particular, questions on satisfaction with } \\
\text { respect the evaluation for relationships, } \\
\text { culture and organizational commitment }\end{array}$ \\
\hline
\end{tabular}

Moreover, the human resources department provided all the data on optional treatments and the information on salary levels of employees for the years 2010, 2011 and 2012. In particular, this information concerned:

- the part of the bonus (expressed in euro) granted to employees of the organization uniformly.

- the quote of incentives (expressed in euro) which has been allocated based on the assessments of the department managers, according to the criteria of merit.

- the salary level, divided into 12 levels, 8 of which are reserved for employees with non-executive work position.

It is worth remembering that usually in PA the monetary incentives are distributed equally among all the employees with the same tenure and position held. The distribution of monetary incentives according to a merit approach has been used only recently. In particular, in 2011 the PA investigated decided to distribute the $47 \%$ of monetary incentives according the position held and the remaining $53 \%$ according the merit approach, whereas in 2013 the percentage are 33\% and $67 \%$ respectively. It is worth noting that the percentage of the merit approach increases because the PA considered to implement a gradual chance of the monetary distribution. The PA decided to implement this change because in 2011 the law L.D.150/09 has been introduced. Moreover, it is important to underline that the monetary incentives are distributed with the same rules in all areas of the organization.

For the sake of simplicity in the following the part of incentives distributed equally among the employees is called historical incentives $\left(I n c_{h}\right)$, whereas the part distributed according to merit criteria is called experimental incentives $\left(\operatorname{Inc}_{e}\right)$.

\section{The Linear Regression Model and the Variables}

As already stated in Section 2, the performance is approximated as a function of the network centrality, modeled considering the relations among the employees, and in particular the informal network (Bonacich 1987; Freeman 1977). The informal network has been built ignoring the vertical relation among supervisor and employees, and has been created by a questionnaire asking with whom and how many times it is necessary to interact to perform the assigned task. In particular, employees were asked to declare up to 10 members of the organization they need to relate more directly and more 
frequently with, to improve or facilitate the conduct of their activities. The Likert scale used ranged from 1 (contacts infrequent, some once a month) to 7 (several times a day). Through the collected information it was possible to build an adjacency, squared and not symmetrical matrix. Only the relationships between employees belonging to the same level have been considered, to detect only those which can be defined "horizontal". Figure 1 shows the built network. Each node in the network represents an employee and the arrows represent the interactions between two employees. It is worth noting that to represent the frequency of the employee interaction each arrow as a weight.

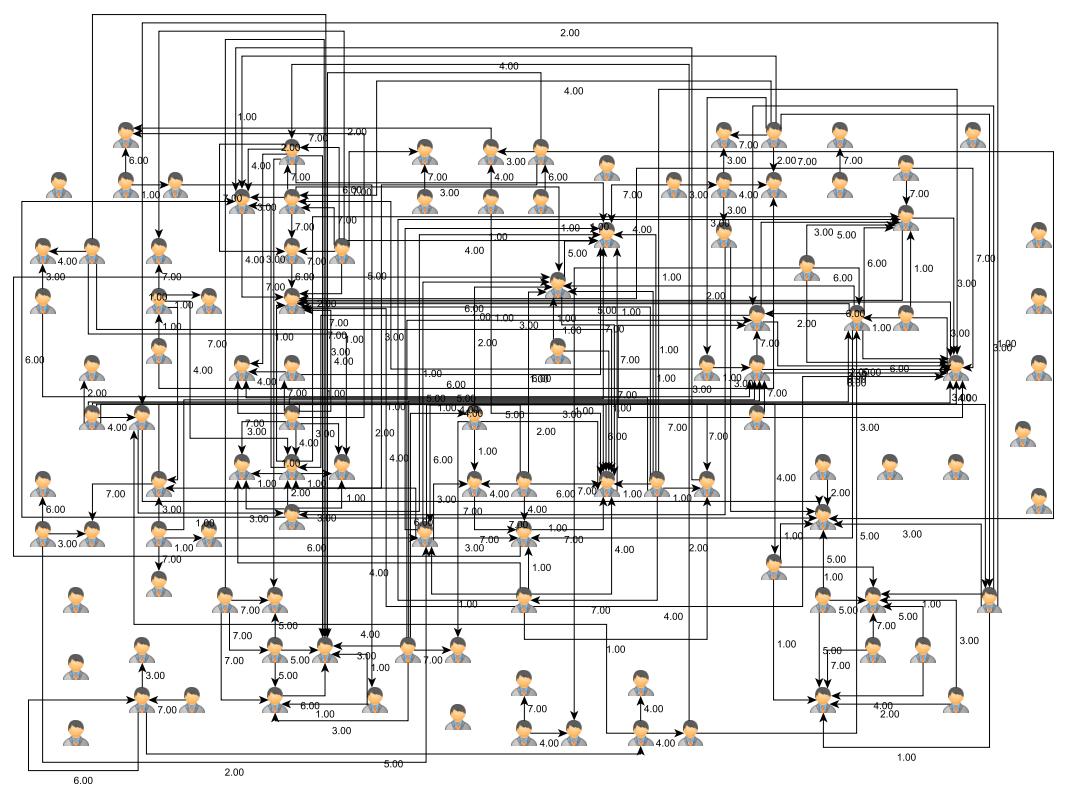

Figure 1. Network of employees.

Starting from the network built, the centrality index (CI) has been defined. As stated in Section 2 the simplest way to measure the importance of a node is to determine its degree, i.e., to count the number of its linked neighbors. The centrality index of employee $i, C I_{i}$, represents the relations between employee $i$ and the other employees and, in particular, indicates how employee $i$ is involved in the activities of the other employees. In formulas,

$$
C I_{i}=\frac{T A C_{i}}{c_{\max }} .
$$

where $T A C_{i}$ is the task advice centrality of employee $i$ and $c_{\text {max }}$ is the maximum number of input connections. The task advice centrality for each node is the sum of all incoming branches (input node degree) multiplied by their weight and it represents the centrality of the individual in the social consulting network. In formulas the task advice centrality of employee $i\left(T A C_{i}\right)$ is

$$
\mathrm{TAC}_{i}=\sum_{j} c_{j, i} g_{j, i}
$$

where $c_{j, i}$ are the incoming branches of employee $i$ and $g_{j, i}$ are the respective weights. The intra-organizational relationship reflects the recognition given to a single employee by his colleagues for both her/his skills and her/his opportunity to participate in working life. In particular, it indicates how a node is necessary to perform the employee activities. Thus, it is a proxy of the employee performance. It is worth noting that as stated in Section 2 the centrality in the advice network is a proxy of individual performance Boissevain and Mitchell (2018). 
The "task advice centrality", represents the relations between employee $i$ and the other employees and, in particular, indicates how employee $i$ is involved in the activities of the other employees. The task advice centrality for each employee represents the centrality of the individual in the social consulting network. The intra-organizational relationship reflects the recognition given to a single employee by her/his colleagues for both her/his skills and her/his opportunity to participate in working life. In particular, it indicates how an employee is necessary to perform the employee activities. Thus, it is a proxy of the employee performance.

Thus, the performance of employee $i$, is evaluated as:

$$
P_{i}=C I_{i}
$$

where $C I_{i}$ is the centrality index.

The other main variables considered in the analysis are the level of salary, the tenure and the type of contract. In this paper, the variables Problem solving, Team working, Self-organizing, Technical knowledge, Customer oriented, considered in Cainarca et al. (2019), have not been included because they do not help in explaining the dependent variables. In fact, the results of the regressions do not change with the inclusion of these variables (see the Appendix of the paper). To verify that the considered variables are independent, the correlation matrix has been evaluated. Table 4 summarizes the values for data collected in February 2011.

Table 4. Pearson Correlations between the independent variables of the linear regression models described in Equations (4) and (5) for data collected in January 2011. * The correlation is significant at the 0.05 level (two-tailed).

\begin{tabular}{rrrrr}
\hline \multicolumn{5}{c}{ Correlations } \\
\hline & SalLev & \multicolumn{1}{c}{ Con } & Ten & \multicolumn{1}{c}{ P } \\
\hline SalLev & 1 & -0.071 & -0.022 & 0.076 \\
Con & -0.071 & 1 & -0.043 & 0.091 \\
Ten & -0.022 & -0.043 & 1 & $0.229^{*}$ \\
$\mathrm{P}$ & 0.076 & 0.091 & $0.229^{*}$ & 1 \\
\hline
\end{tabular}

Table 4 shows that the correlations' values are small and then the linear regression with these variables can be performed.

The linear regression for the two cases of historical and experimental incentives is:

$$
\begin{array}{r}
\text { Inc }_{h, i}=\beta_{o}+\beta_{1} \text { SalLev }_{i}+\beta_{2} \text { Con }_{i}+\beta_{3} \text { Ten }_{i}+ \\
\beta_{4} P_{i}+\beta_{5} \chi_{i}+\epsilon_{i} \\
\text { Inc }_{e, i}=\beta_{0}+\beta_{1} \text { SalLev }_{i}+\beta_{2} \text { Con }_{i}+\beta_{3} \text { Ten }_{i}+ \\
\beta_{4} P_{i}+\beta_{5} \chi_{i}+\epsilon_{i}
\end{array}
$$

In the regression analysis the incentives $I n c_{h, i}$ and $I n c_{e, i}$ are the dependent variable, whereas, the Level of salary, the Type of contract, the Tenure and the Performance are the independent variables. Table 5 summarizes all the variables used in the regression.

To verify the hypothesis $\mathrm{H} 2$ defined in Section 2, the independent variable is the performance $\mathrm{P}$ of year 2013 and the dependent variables are the level of salary, the type of contract, the tenure and the experimental and historical incentives of year 2011. Table 6 summarizes the variables used for this regression. 
Table 5. Variables of the linear regression models described in Equations (4) and (5).

\begin{tabular}{|c|c|}
\hline Variable & Description \\
\hline \multicolumn{2}{|c|}{ Dependent variables } \\
\hline $\begin{array}{l}\operatorname{Inc} c_{h} \\
\operatorname{Inc} c_{e}\end{array}$ & $\begin{array}{l}\text { historical monetary incentive received by each employee } \\
\text { experimental monetary incentive received by each employee }\end{array}$ \\
\hline \multicolumn{2}{|c|}{ Independent variables } \\
\hline SalLev & level of salary \\
\hline Con & type of contract \\
\hline Ten & tenure \\
\hline $\mathrm{P}$ & performance \\
\hline \multicolumn{2}{|c|}{ Control variables } \\
\hline Age & Age \\
\hline Gender & gender \\
\hline FPT & female part-time \\
\hline Area & area \\
\hline
\end{tabular}

Table 6. Variables of the linear regression model described in Equation (6).

\begin{tabular}{|c|c|}
\hline Variable & Description \\
\hline \multicolumn{2}{|c|}{ Dependent variables } \\
\hline $\mathrm{P}$ & performance \\
\hline \multicolumn{2}{|c|}{ Independent variables } \\
\hline $\begin{array}{l}\operatorname{Inc} c_{h} \\
I n c_{e} \\
\text { SalLev } \\
\text { Ten }\end{array}$ & $\begin{array}{c}\text { historical monetary incentive received by each employee year } 2011 \\
\text { experimental monetary incentive received by each employee year } 2011 \\
\text { level of salary } \\
\text { tenure }\end{array}$ \\
\hline \multicolumn{2}{|c|}{ Control variables } \\
\hline $\begin{array}{l}\text { Age } \\
\text { Gender } \\
\text { FPT } \\
\text { Area }\end{array}$ & $\begin{array}{l}\text { Age } \\
\text { gender } \\
\text { female part-time } \\
\text { area }\end{array}$ \\
\hline
\end{tabular}

Table 7 shows the correlation between the independent variables of the linear regression model described in Equation (6) for data collected in January 2013.

Table 7. Pearson correlations between the independent variables of the linear regression model described in Equation (6) for data collected in January 2013. ** The correlation is significant at the 0.01 level (two-tailed). * The correlation is significant at the 0.05 level (two-tailed).

\begin{tabular}{rrrrrr}
\hline Correlations & \multicolumn{1}{c}{ Con } & en & \multicolumn{1}{c}{ Inch } & Ince \\
\hline & SalLev & \multicolumn{1}{c}{ Con } \\
\hline SalLev & 1 & -0.071 & -0.023 & $0.246^{*}$ & $0.368^{* *}$ \\
Con & -0.071 & 1 & -0.047 & $0.789^{* *}$ & $0.334^{* *}$ \\
Ten & -0.023 & -0.047 & 1 & -0.021 & 0.021 \\
Inch & $0.246^{*}$ & $0.789^{* *}$ & -0.021 & 1 & $0.605^{* *}$ \\
Ince & $0.368^{* *}$ & $0.334^{* *}$ & 0.021 & $0.605^{* *}$ & 1 \\
\hline
\end{tabular}

As there are significant correlations between some independent variables, the multicollinearity analysis has been performed. Table 8 shows the Variance Inflation Factor (VIF) and its reciprocal, that is called Tolerance, of the independent variables of the linear regression model described in Equation (6). 
VIF quantifies the extent of correlation between one predictor and the other predictors in a model James et al. (2013).

Table 8. Variance Inflation Factor (VIF) and Tolerance of the independent variables of the linear regression model described in Equation (6).

\begin{tabular}{lcc}
\hline & \multicolumn{2}{c}{ Collinearity Statistics } \\
\hline & VIF & Tolerance \\
Level of salary & 1.934 & 0.517 \\
Type of contract & 3.730 & 0.268 \\
Tenure & 2.138 & 0.468 \\
Historical incentive 2011 & 4.958 & 0.202 \\
Experimental incentive 2011 & 1.892 & 0.528 \\
Age & 2.361 & 0.424 \\
Gender & 1.330 & 0.752 \\
Area 1 & 1.708 & 0.586 \\
Area 2 & 2.010 & 0.498 \\
Area 3 & 2.143 & 0.467 \\
Area 4 & 1.864 & 0.537 \\
\hline
\end{tabular}

All the VIF values are such that the linear regression described in Equation (6) can be performed. See James et al. (2013) for details. The linear regression is:

$$
\begin{array}{r}
P_{i}=\beta_{o}+\beta_{1} \operatorname{SalLev}_{i}+\beta_{2} \operatorname{Con}_{i}+\beta_{3} \operatorname{Ten}_{i}+ \\
\beta_{4} \operatorname{Inc}_{h, i}+\beta_{5} \operatorname{Inc}_{e, i}+\beta_{5} \chi_{i}+\epsilon_{i}
\end{array}
$$

In the regression analysis the performance $P_{i}$ is the dependent variable, whereas, the Level of salary, the Type of contract, the Tenure and the historical and experimental incentives are the independent variables.

\section{Results of the Linear Regression Analysis}

To investigate $\mathrm{H} 1$ the regressions described in Equations (4) and (5) have been performed and results are shown in Tables 9.

Table 9. Results of linear regressions described in Equations (4) and (5). ${ }^{* *}$ Significant at the 5\%. *** Significant at the $1 \%$.

\begin{tabular}{lrrrrrr}
\hline & \multicolumn{2}{c}{ Historical Incentive 2011 } & \multicolumn{3}{c}{ Experimental Incentive 2011 } \\
\hline & Beta & Err. Std. & Sign. & Beta & Err. Std. & Sign. \\
\hline Constant & & 0.54 .168 & & & 0.789 .366 & $* *$ \\
Level of salary & 0.364 & 0.5 .392 & $* * *$ & 0.414 & 0.78 .761 & $* * *$ \\
Type of contract & 0.756 & 0.32 .797 & $* * *$ & 0.327 & 0.34 .903 & $* * *$ \\
Tenure & 0.044 & 2.805 & & 0.041 & 0.9 .750 & \\
Performance 0.011 & 0.013 & 1.080 & & 0.328 & 7.602 & $* * *$ \\
Age & -0.039 & 3.946 & & -0.111 & 0.7 .777 & \\
Gender & -0.099 & 0.7 .352 & & 0.057 & 0.62 .962 & \\
Area 1 & -0.060 & 0.7 .128 & & -0.210 & 0.02 .186 & $* *$ \\
Area 2 & -0.183 & 0.8 .150 & $* *$ & -0.259 & 0.09 .381 & $*$ \\
Area 3 & -0.080 & 0.7 .020 & & -0.146 & 0.31 .025 & \\
Area 4 & -0.093 & 0.1 .050 & & -0.085 & 0.29 .800 & \\
\hline$R^{2}$ adjusted & 0.707 & & & 0.377 & & \\
ANOVA Test F & 0.5 .838 & $* * *$ & 7.246 & $* *$ & \\
\hline
\end{tabular}


In the case of linear regression described in Equation (4) (historical incentives), the value of $R^{2}$ adjusted (adjusted r-squared) is 0.707 , confirming that the choice of the dependent variables are sufficient for the explanation of $I n c_{h}$. The ANOVA test is equal to 25.838 confirming that the model fits the data considered. Looking at the regressors' coefficients, the greatest weights are the type of contract and the salary level. In the case of the type contract, the value of beta is 0.756 , that indicates that the historical incentive is directly proportional to the percentage of working time. In these terms, the greater the share of part-time contract, the lower the amount of incentives received is, regardless of any assessment of individual performance. For the historical incentives, the remuneration is strictly linked to the level of contract. In this case, the historical incentives are assigned according to parameters not linked to the individual performance, because instead of the performance the discriminant variables are the type of contract and the salary level. These variables are linked to the organization plan.

In the case of linear regression described in Equation (5) (experimental incentives) the value of $R^{2}$ adjusted (adjusted r-squared) is 0.377 . It can be considered a good result because this work attempts to predict human behavior. The ANOVA test is equal to 7.246 confirming that the model fits the data considered. The tenure and type of contract variables are important also in this case whereas the tenure is not. These results confirm that part of the experimental incentives is distributed among the employees considering the position held. It is worth noting that the value of $\beta$ of the performance in the experimental case is equal to 0.328 showing that the monetary incentives are linked to the performance. Thus, the regression demonstrates that employees that have a better performance are better rewarding with the monetary incentives. These results verify the hypothesis H1. Moreover, it is worth noting that the monetary incentives are a reward for the year in which they are distributed. In order to investigate if they become a stimulus for the next year, the regression defined in Equation (6) has been studied. The results are shown in Table 10.

Table 10. Results of linear regressions described in Equation (6). ${ }^{* *}$ Significant at the $5 \% .{ }^{* *}$ Significant at the $1 \%$.

\begin{tabular}{|c|c|c|c|}
\hline & \multicolumn{3}{|c|}{ Performance 2013} \\
\hline & Beta & Err. Std. & Sign. \\
\hline Constant & & 16.394 & \\
\hline Level of salary & 0.059 & 1.894 & \\
\hline Type of contract & 0.091 & 14.152 & \\
\hline Tenure & 0.116 & 0.172 & \\
\hline Historical incentive 2011 & -0.379 & 0.007 & ** \\
\hline Experimental incentive 2011 & 0.405 & 0.001 & $* * *$ \\
\hline Age & -0.005 & 0.248 & \\
\hline Gender & 0.053 & 2.387 & \\
\hline Area 1 & 0.099 & 3.692 & \\
\hline Area 2 & -0.178 & 3.777 & \\
\hline Area 3 & -0.430 & 2.973 & $* * *$ \\
\hline Area 4 & -0.265 & 3.746 & ** \\
\hline R square adjusted & 0.225 & & \\
\hline ANOVA Test F & 3.690 & $* * *$ & \\
\hline
\end{tabular}

Looking at the regressors' coefficients, the greatest weights are the incentives. The value of beta of the experimental incentives is 0.405 , that indicates that the experimental incentive is directly proportional to the employee performance, whereas the value of beta of the historical incentives is -0.379 showing that the historical incentive is inversely proportional to the employees performance. These results confirm that if the monetary incentives are distributed according to a merit criterion, they work as stimulus to improve the employee performance. Instead the historical incentives work in the opposite direction, in fact the employees know that the monetary incentives are distributed based on tenure and level of salary and not on the basis of parameters linked to individual performance. 
The value of $R^{2}$ adjusted (adjusted r-squared) is 0.225 and the ANOVA test is equal to 3.690 confirming that the model fits the data considered.

Finally, comparing the results of the investigation published in Cainarca et al. (2019) with the ones obtained here, we also address the reverse causality issue because if the monetary incentives induce a virtuous employee behavior, it means that the monetary incentives are distributed according the employee performance, which means that the monetary incentives represent a bonus for the employee performance.

\section{Discussion and Conclusions}

This study is one of the first attempts, to study the distribution of monetary incentives in the public sector after the introduction of a merit-based incentive system that follows a "rank-order tournament" logic. The management has disclosed transparently what the objectives of the incentive system are, trying as much as possible to ensure fairness in the evaluation criteria.

The relation between the employee monetary incentives and employee performance has been investigated using a regression model. The employee performance has been approximated with the centrality index. The theoretical and empirical aspect employed for the design of the employee performance and of the mechanism of monetary incentives distribution have been presented and discussed.

The results have shown that the monetary incentives distributed with a merit logic depends on the employee performance and they are a stimulus for the next period of evaluation. It is worth noting that using an ordinal, and not cardinal system, to compare the performance of individual employees, they do not have to compete only with themselves, but their performance will be evaluated in relation to the ones of others and the result of the comparison will be known only at the end. This study observed the results of the interaction between monetary incentives and employee performance for two cycle of application. The use of the meritocratic system in the first period of evaluation increases employee responsiveness to incitation from managers, as suggested by Homans and other supporters of the theory of social exchange Homans (1974). The use of the meritocratic system in the second period of evaluation show that the bonus is a stimulus for the next period of evaluation. Furthermore, results have confirmed that the monetary incentives distributed with a merit logic influence positively the employee performance in the short term.

It is worth noting that the change in the PA can be possible only by laws, but it is important to investigate the effects of laws to give information to the politicians. The main limitation of the study is the dataset. In fact, in this paper only one local PA has been considered. Another limitation is the methodology used. Even if linear regression analysis is the most common method used (Blalock 2017b; Fox 1997), other methods like nonlinear regressions and the data envelopment analysis can be used as robustness check. To overcome these limitations, in the next future, other local PA will be included in the analysis and other methodologies such as nonlinear regression, data envelopment analysis and machine learning techniques, if the number of observations will be sufficient, will be adopted. The final step will be to develop an agent-based model where the agents represent the employees to provide a tool very suitable to make classical what-if analysis. In particular, it will be a sort of computational laboratory where to perform experiments and find the more convenient policy to distribute the monetary incentives and to improve the employee performance. Finally, it is worth remembering that the agent-based model will be a useful tool not only for Public Administration but also for private companies.

Author Contributions: L.P., F.D. and G.C.C. designed research, performed research, analyzed data, and wrote the paper. All authors have read and agreed to the published version of the manuscript.

Funding: This research received no external funding.

Acknowledgments: The authors gratefully acknowledge the Camera di Commercio di Genova for financial support.

Conflicts of Interest: The authors declare no conflict of interest. 


\section{Appendix A}

Tables A1 and A2 show that including the "life skills" variables defined in Cainarca et al. (2019), the results discussed in Section 5 and 6 are confirmed.

Table A1. Results of linear regressions described in Equations (4) and (5) considering all the interactive variables described in Cainarca et al. (2019). ${ }^{*}$ Significant at the 10\%. ${ }^{* * *}$ Significant at the $1 \%$.

\begin{tabular}{lrrrrrr}
\hline & \multicolumn{3}{c}{ Historical Incentive 2011 } & \multicolumn{3}{c}{ Experimental Incentive 2011 } \\
\hline & Beta & Err. Std. & Sign. & Beta & Err. Std. & Sign. \\
\hline Constant & & 0.007 & $* * *$ & & 0.006 & $* * *$ \\
Level of salary & 0.322 & 0.000 & $* * *$ & 0.315 & 0.002 & $* * *$ \\
Type of contract & 0.926 & 0.000 & $* * *$ & 0.571 & 0.001 & $* * *$ \\
Tenure & -0.045 & 0.446 & & -0.109 & 0.357 & \\
Performance 0.011 & 0.034 & 0.441 & & 0.404 & 0.000 & $* * *$ \\
Age & -0.059 & 0.319 & & -0.019 & 0.875 & \\
Problem solving & -0.092 & 0.073 & $*$ & -0.082 & 0.422 & \\
Self-organizing & 0.056 & 0.255 & & 0.130 & 0.186 & \\
Technical knowledge & 0.014 & 0.758 & & 0.039 & 0.669 & \\
Customer oriented & 0.066 & 0.211 & & 0.023 & 0.828 & \\
Women part-time & 0.021 & 0.803 & & 0.265 & 0.116 & \\
Area 1 & -0.041 & 0.422 & & -0.028 & 0.783 & \\
Area 2 & -0.37 & 0.492 & & -0.093 & 0.398 & \\
Area 3 & 0.041 & 0.496 & & -0.081 & 0.499 & \\
Area 4 & -0.029 & 0.595 & & 0.043 & 0.694 & \\
\hline$R^{2}$ adjusted & 0.841 & & & 0.354 & & \\
ANOVA Test F & 0.9 .125 & 0.000 & $* * *$ & 4.943 & 0.000 & $* * *$ \\
\hline
\end{tabular}

Table A2. Results of linear regressions described in Equation (6) considering all the life skill variables described in Cainarca et al. (2019). ** Significant at the 5\%. ** Significant at the $1 \%$.

\begin{tabular}{lrrr}
\hline \multicolumn{3}{c}{ Performance 2013 } \\
\hline & Beta & Err. Std. & Sign. \\
\hline Constant & & 0.646 & \\
Level of salary & 0.163 & 0.185 & \\
Type of contract & 0.132 & 0.668 & \\
Tenure & 0.138 & 0.296 & \\
Historical incentive 2011 & -0.393 & 0.155 & \\
Experimental incentive 2011 & 0.332 & 0.004 & $* * *$ \\
Age & -0.038 & 0.774 & \\
Problem solving & -0.029 & 0.799 & \\
Team working & 0.246 & 0.019 & $* * *$ \\
Self-organizing & 0.016 & 0.887 & \\
Technical knowledge & -0.097 & 0.341 & \\
Customer oriented & -0.146 & 0.194 & \\
Women part-time & -0.020 & 0.915 & \\
Area 1 & 0.026 & 0.817 & \\
Area 2 & -0.169 & 0.164 & \multirow{2}{*}{$* * *$} \\
Area 3 & -0.382 & 0.005 & $* * *$ \\
Area 4 & -0.281 & 0.020 & $*$ \\
\hline R square adjusted & 0.239 & & \\
ANOVA Test F & 3.001 & 0.001 & $*$ \\
\hline & & & \\
\hline
\end{tabular}

Moreover, it is possible to observe the Area 3 and 4 with respect to the gender. The interactive variables have been defined multiplying the original independent variables. Table A3 shows the results. It is worth noting that in area 3 are the women to have a negative relation to the performance whereas in area 4 are the men. 
Table A3. Results of linear regressions described in Equation (6) considering some interactive variables. ** Significant at the $5 \%$. ** Significant at the $1 \%$.

\begin{tabular}{lrrr}
\hline & \multicolumn{3}{c}{ Performance 2013 } \\
\hline & Beta & Err. Std. & Sign. \\
\hline Constant & & 15.816 & \\
Level of salary & 0.050 & 1.839 & \\
Tenure & 0.114 & 0.169 & \\
Historical incentive 2011 & -0.313 & 0.006 & $* *$ \\
Experimental incentive 2011 & 0.423 & 0.001 & $* * *$ \\
Age & -0.019 & 0.245 & \\
Area 1 & 0.110 & 3.620 & \\
Area 2 & -0.154 & 3.676 & \\
Women part-time & 0.007 & 3.432 & \\
Women Area 3 & -0.437 & 3.190 & $* * *$ \\
Men Area 3 & -0.176 & 3.953 & \\
Women Area 4 & -0.161 & 4.630 & \\
Men Area 4 & -0.239 & 4.618 & $* * *$ \\
\hline R square adjusted & 0.232 & & \\
ANOVA Test F & 3.569 & 0.001 & $* * *$ \\
\hline
\end{tabular}

\section{References}

Aalbers, Rick, and Wilfred Dolfsma. 2015. Innovation Networks: Managing the Networked Organization. London and New York: Routledge.

Albaum, Gerald. 1997. The likert scale revisited. Journal-Market Research Society 39: 331-48. [CrossRef]

Alkahtani, Ali. 2015. Organizational citizenship behavior (ocb) and rewards. International Business Research 8: 210. [CrossRef]

Andersen, Lotte Bøgh. 2007. Professional norms, public service motivation and economic incentives. Paper presented at the EGPA Conference 2007, Madrid, Spain, September 19-22.

Appelbaum, Eileen. 2000. Manufacturing Advantage: Why High-Performance Work Systems Pay off. New York: Cornell University Press.

Atkinson, Michael M., Murray Fulton, and Boa Kim. 2014. Why do governments use pay for performance? contrasting theories and interview evidence. Canadian Public Administration 57: 436-58. [CrossRef]

Baldwin, Timothy T., Michael D. Bedell, and Jonathan L. Johnson. 1997. The social fabric of a team-based mba program: Network effects on student satisfaction and performance. Academy of Management Journal 40: 1369-97.

Banno, Mariasole, and Francesca Sgobbi. 2010. NOV-DEC. Firm participation in financial incentive programmes: The case of subsidies for outward internationalisation. Journal of Policy Modeling 32: 792-803. [CrossRef]

Behn, Robert D. 1995. The big question of public management. Public Administration Review 55: 313-24. [CrossRef]

Bellé, Nicola. 2015. Performance-related pay and the crowding out of motivation in the public sector: A randomized field experiment. Public Administration Review 75: 230-41. [CrossRef]

Blalock, Hubert M. 2017a. Measurement in the Social Sciences. New York: Routledge.

Blalock, Hubert M., Jr. 2017b. Causal Models in the Social Sciences. New York: Routledge.

Boissevain, Jeremy, and J. Clyde Mitchell. 2018. Network Analysis: Studies in Human Interaction. Berlin: Walter de Gruyter $\mathrm{GmbH} \& \mathrm{Co}$ KG.

Boland, Tony, and Alan Fowler. 2000. A systems perspective of performance management in public sector organisation. International Journal of Public Sector Management 13: 417-46. [CrossRef]

Bonacich, Phillip. 1987. Power and centrality: A family of measures. American Journal of Sociology 92: 1170-82. [CrossRef]

Boxall, Peter, and John Purcell. 2008. Strategy and Human Resource Management. Series: Management, work and organisations; New York: Palgrave Macmillan.

Bradler, Christiane, Robert Dur, Susanne Neckermann, and Arjan Non. 2016. Employee recognition and performance: A field experiment. Management Science 62: 3085-99. [CrossRef] 
Brass, Daniel J., and Marlene E. Burkhardt. 1992. Centrality and power in organizations. Networks and Organizations: Structure, Form, and Action 191: 198-213.

Brayfield, Arthur H., and Walter H. Crockett. 1955. Employee attitudes and employee performance. Psychological Bulletin 52: 396. [CrossRef] [PubMed]

Brignall, S., and S. Modell. 2000. An istitutional persperctive on performance measurement and management in the "new public sector". Management Accounting Research 11: 281-306. [CrossRef]

Burgess, Simon, Carol Propper, Marisa Ratto, and Emma Tominey. 2017. Incentives in the public sector: Evidence from a government agency. Economic Journal 127: F117-F141. [CrossRef]

Cainarca, Gian Carlo, Francesco Delfino, and Linda Ponta. 2019. The effect of monetary incentives on individual and organizational performance in an italian public institution. Administrative Sciences 9: 72. [CrossRef]

Chang, Eunmi. 2011. Motivational effects of pay for performance: A multilevel analysis of a korean case. The International Journal of Human Resource Management 22: 3929-48. [CrossRef]

Cook, Karen S., Richard M. Emerson, Mary R. Gillmore, and Toshio Yamagishi. 1983. The distribution of power in exchange networks: Theory and experimental results. American Journal of Sociology 89: 275-305. [CrossRef]

Dahlström, Carl, and Victor Lapuente. 2017. Organizing Leviathan: Politicians, Bureaucrats, and the Making of Good Government. Cambridge: Cambridge University Press.

Davidson, Stephen M., Larry M. Manheim, Mina M. Hohlen, Stephen M. Werner, Beth K. Yudkowsky, and Gretchen V. Fleming. 1992. Prepayment with office-based physicians in publicly funded programs: Results from the children's medicaid program. Pediatrics 89: 761-67.

Delery, John E., and Jason D. Shaw. 2001. The strategic management of people in work organizations: Review, synthesis, and extension. Research in Personnel and Human Resources Management 20: 165-97.

Dowling, Bernard, and Ray Richardson. 1997. Evaluating performance-related pay for managers in the national health service. International Journal of Human Resource Management 8: 348-66. [CrossRef]

Durant, Robert F., Robert Kramer, James L. Perry, Debra Mesch, and Laurie Paarlberg. 2006. Motivating employees in a new governance era: The performance paradigm revisited. Public Administration Review 66: 505-14. [CrossRef]

Fox, John. 1997. Applied Regression Analysis, Linear Models, and Related Methods. Los Angeles: Sage Publications, Inc. Freeman, Linton. 1977. A Set of Measures of Centrality Based on Betweenness. Sociometry 40: 35-41. [CrossRef]

Frey, Bruno S., Fabian Homberg, and Margit Osterloh. 2013. Organizational control systems and pay-for-performance in the public service. Organization Studies 34: 949-72. [CrossRef]

Gordon, Rachel A. 2015. Regression Analysis for the Social Sciences. New York: Routledge.

Gruening, Gernod. 2001. Origin and theoretical basis of new public management. International Public Management Journal 4: 1-25. [CrossRef]

Homans, George C. 1974. Social Behavior: Its Elementary Forms, revised ed. New York: Harcourt Brace Jovanovich. Hood, Christopher. 1991. A public management for all seasons? Public Administration 69: 3-19. [CrossRef]

Hood, Christopher. 1995. The "new public management" in the 1980s: Variations on a theme. Accounting, Organizations and Society 20: 93-109. [CrossRef]

Hood, Christopher, and Michael W. Jackson. 1991. Administrative Argument. Aldershot: Dartmouth. Publishing Group.

Ibarra, Herminia, and Steven B. Andrews. 1993. Power, social influence, and sense making: Effects of network centrality and proximity on employee perceptions. Administrative Science Quarterly 38: 277-303. [CrossRef]

James, Gareth, Daniela Witten, Trevor Hastie, and Robert Tibshirani. 2013. An Introduction to Statistical Learning. New York: Springer, vol. 112.

Johnsen, Åge. 2019. Does formal strategic planning matter? an analysis of strategic management and perceived usefulness in norwegian municipalities. International Review of Administrative Sciences. UNSP 0020852319867128.

Katz, Harry C., Thomas A. Kochan, and Mark R. Weber. 1985. Assessing the effects of industrial relations systems and efforts to improve the quality of working life on organizational effectiveness. Academy of Management Journal 28: 509-26.

Kearney, Richard. 2018. Public Sector Performance: Management, Motivation, and Measurement. New York: Routledge.

Kitsak, Maksim, Lazaros K. Gallos, Shlomo Havlin, Fredrik Liljeros, Lev Muchnik, H. Eugene Stanley, and Hernán A. Makse. 2010. Identification of influential spreaders in complex networks. Nature Physics 6: 888. [CrossRef]

Koliba, Christopher J., Jack W. Meek, Asim Zia, and Russell W. Mills. 2017. Governance Networks in Public Administration and Public Policy. New York: Routledge. 
Lah, T. J. and James L. Perry. 2008. The diffusion of the civil service reform act of 1978 in oecd countries: A tale of two paths to reform. Review of Public Personnel Administration 28: 282-299. [CrossRef]

Lăzăroiu, George. 2015. Employee motivation and job performance. Linguistic and Philosophical Investigations 14: 97-102.

Lazear, Edward P., and Sherwin Rosen. 1981. Rank-order tournaments as optimum labor contracts. Journal of Political Economy 89: 841-64. [CrossRef]

Lepak, David P., Hui Liao, Yunhyung Chung, and Erika E. Harden. 2006. A conceptual review of human resource management systems in strategic human resource management research. Research in Personnel and Human Resources Management 25: 217-71.

Levitats, Zehavit, and Eran Vigoda-Gadot. 2019. Emotionally engaged civil servants: Toward a multilevel theory and multisource analysis in public administration. Review of Public Personnel Administration. in press. [CrossRef]

Lü, Linyuan, Tao Zhou, Qian-Ming Zhang, and H. Eugene Stanley. 2016. The h-index of a network node and its relation to degree and coreness. Nature Communications 7: 10168.

Luthans, Fred. 1973. The contingency theory of management: A path out of the jungle. Business Horizons 16: 67-72. [CrossRef]

Mace, Cecil Alec. 1935. Incentives. some experimental studies. Industrial Health Research Board Report. Medical Research Council 72: 69.

Maier, Norman Raymond Frederick. 1955. Psychology in Industry: A Psychological Approach to Industrial Problems. Boston: Houghton Mifflin.

Mao, Connie X., and Jamie Weathers. 2019. Employee treatment and firm innovation. Journal of Business Finance $\mathcal{E}$ Accounting 46: 977-1002.

Mariano, Enzo Barberio, Vinicius Amorim Sobreiro, and Daisy Aparecida do Nascimento Rebelatto. 2015. Human development and data envelopment analysis: A structured literature review. Omega 54: 33-49. [CrossRef]

Marin-Garcia, Juan A., and Juan Martinez Tomas. 2016. Deconstructing amo framework: A systematic review. Intangible Capital 12: 1040-87. [CrossRef]

Mostafa, Ahmed Mohammed Sayed, Julian Seymour Gould-Williams, and Paul Bottomley. 2015. High-performance human resource practices and employee outcomes: The mediating role of public service motivation. Public Administration Review 75: 747-57. [CrossRef]

Organ, Dennis W. 1988. Organizational Citizenship Behavior: The Good Soldier Syndrome. Lexington: Lexington Books.

Paauwe, Jaap. 2009. Hrm and performance: Achievements, methodological issues and prospects. Journal of Management Studies 46: 129-42. [CrossRef]

Pearce, Jone L., and James L. Perry. 1983. Merit pay: A longitudinal analysis. Public Administration Review 43: 315-25. [CrossRef]

Perry, James L. 1996. Measuring public service motivation: An assessment of construct reliability and validity. Journal of Public Administration Research and Theory 6: 5-22. [CrossRef]

Perry, James L., and Wouter Vandenabeele. 2015. Public service motivation research: Achievements, challenges, and future directions. Public Administration Review 75: 692-99. [CrossRef]

Perry, James L., and Lois Recascino Wise. 1990. The motivational bases of public service. Public Administration Review 50: 367-373. [CrossRef]

Perry, James L., Trent A. Engbers, and So Yun Jun. 2009. Back to the future? performance-related pay, empirical research, and the perils of persistence. Public Administration Review 69: 39-51. [CrossRef]

Rainey, Hal G. 2009. Understanding and Managing Public Organizations. San Francisco: John Wiley \& Sons.

Ritz, Adrian, Gene A. Brewer, and Oliver Neumann. 2016. Public service motivation: A systematic literature review and outlook. Public Administration Review 76: 414-26. [CrossRef]

Salzman, James. 2000. Labor rights, globalization and institutions: The role and influence of the organization for economic cooperation and development. Michigan Journal of International Law 21: 769-975. [CrossRef]

Sawitri, Dyah, Endang Suswati, and Khasbulloh Huda. 2016. The impact of job satisfaction, organization commitment, organization citizenship behavior (ocb) on employees'performance. International Journal of Organizational Innovation 9: 24-45.

Shaw, Jason D., Michelle K. Duffy, Atul Mitra, Daniel E. Lockhart, and Matthew Bowler. 2003. Reactions to merit pay increases: A longitudinal test of a signal sensitivity perspective. Journal of Applied Psychology 88: 538. [CrossRef] [PubMed] 
Shields, John, Michelle Brown, Sarah Kaine, Catherine Dolle-Samuel, Andrea North-Samardzic, Peter McLean, Robyn Johns, Patrick O'Leary, Jack Robinson, and Geoff Plimmer. 2015. Managing Employee Performance $\mathcal{E}$ Reward: Concepts, Practices, Strategies. Cambridge: Cambridge University Press.

Skinner, Burrhus Frederic. 1969. Contingencies of reinforcement. New York: Appleton-Century-Crofts

Smith, C. Ann, Dennis W. Organ, and Janet P. Near. 1983. Organizational citizenship behavior: Its nature and antecedents. Journal of Applied Psychology 68: 653-63. [CrossRef]

Spano, Alessandro, and Patrizio Monfardini. 2018. Performance-related payments in local governments: Do they improve performance or only increase salary? International Journal of Public Administration 41: 321-34. [CrossRef]

Stajkovic, Alexander D., and Fred Luthans. 1997. A meta-analysis of the effects of organizational behavior modification on task performance, 1975-95. Academy of Management Journal 40: 1122-49.

Umans, Timurs, Elin Smith, William Andersson, and William Planken. 2018. Top management teams' shared leadership and ambidexterity: The role of management control systems. International Review of Administrative Sciences. in press.

Van Eerde, Wendelien, and Henk Thierry. 1996. Vroom's expectancy models and work-related criteria: A meta-analysis. Journal of Applied Psychology 81: 575. [CrossRef]

Viteles, Morris S. 1953. Motivation and Morale in Industry. New York: Norton.

Weibel, Antoinette, Katja Rost, and Margit Osterloh. 2009. Pay for performance in the public sector-Benefits and (hidden) costs. Journal of Public Administration Research and Theory 20: 387-412. [CrossRef]

Whitford, Andrew B. 2018. Incentives and Tournaments in Public Organizations. Perspectives on Public Management and Governance 1: 177-94. [CrossRef]

Yating, Wang, and Yang Yang. 2017. Job performance modeling: A holistic theoretical analysis. Management Science and Engineering 11: 20-29.

(C) 2020 by the authors. Licensee MDPI, Basel, Switzerland. This article is an open access article distributed under the terms and conditions of the Creative Commons Attribution (CC BY) license (http:/ / creativecommons.org/licenses/by/4.0/). 